\section{A general routine for computing selected multiple comparisons procedures}

RANDALL M. PARKER

University of Texas at Austin, Austin. Texas 78712

Frequently, researchers employing analysis of variance (ANOVA) are interested in the differences between specific means or sets of means within the total set of means. A wide variety of statistical techniques exist to make such multiple comparisons. MULTCOM, an extention of Parker (1971), is a computer program which runs two extremely flexible techniques, planned orthogonal comparisons (POC) and Scheffé's test (ST) (see Hays, 1963). POC is a powerful approach, while ST is conservative. The basic formula for both is:

$$
F=\frac{\left(C_{1} \bar{X}_{1}+C_{1} \bar{X}_{2}+\cdots+C_{k} \bar{X}_{k}\right)^{2}}{\operatorname{MSE}\left(\frac{C_{1}{ }^{2}}{n_{1}}+\frac{C_{2}{ }^{2}}{n_{2}}+\cdots \frac{C_{k}{ }^{2}}{n_{k}}\right)},
$$

where $\mathrm{C}=$ coefficients for a comparison, $\overline{\mathrm{X}}=$ the means, $\mathrm{k}=$ the number of means or groups, $\mathrm{MSE}=$ the mean square error term for an analy sis of variance, and $n=$ the number of observations or Ss in a group.

For POC, one evaluates the above F with $\mathrm{k}-1 \mathrm{df}$ and MSE df (usually $\mathrm{N}-\mathrm{k}$ ). Naturally, the comparisons must be independent or orthogonal, and this requirement may prove too confining in some circumstances. If so, one may turn to ST. ST, however, requires the overall $\mathrm{F}$ for the ANOVA to be significant, whereas the POC procedure does not.

ST is computed using the same above formula, without the orthogonality restrictions. Then a corrected $F$ is obtained as follows:

$$
F^{\prime}=\frac{F}{k-1}
$$

$F^{\prime}$ is then evaluated with $\mathrm{k}-1$ and MSE df. One can see that with a large number of groups, a relatively large effect must be present for ST to detect it.

Language and Computer. MULTCOM is written in CDC FORTRAN, but should be easily adapted to any computer with a FORTRAN compiler. It is a fast-running program, requiring only 2,300 words of memory.

Input. The input parameters include the number of group means to be compared, the number of observations per group, the MSE term, the degrees of freedom for MSE (if blank, $\mathrm{N}-\mathrm{k}$ df are assumed), the tabled $F$ value at the desired level of significance (optional), the group means, the number of observations for each group, and the coefficients for each comparison. MULTCOM will solve any number of problems; each problem may consist of a maximum of 20 means and 100 comparisons.

Output. The output includes a listing of the input parameters, the arithmetic difference among the means, the smallest statistically significant difference among the means (only if the $F$ value parameter is input), the $F$ value, the exact probability of the $F$ value, and a listing of whether all combinations of the comparisons taken two at a time are orthogonal. Subroutine PRTS and function PRBF (Veldman, 1967) are called.

Availability. A listing of MULTCOM is available free of charge from Randall M. Parker, Department of Special Education, University of Texas, Austin, Texas 78712.

\section{REFERENCES}

Hays, W. Statistics for psychologists. New York: Holt, Rinehart, \& Winston, 1963.

Parker, R. A program of Scheffé's method. Educational \& Psychological Measurement, 1971, 31, 761.

Veldman, D. FORTRAN programming for the behavioral sciences. New York: Holt, Rinehart, \& Winston, 1967. 